\title{
High-risk cardiac surgery: Time to explore a new paradigm
}

\section{Daniel J. Goldstein, MD, ${ }^{a}$ and Edward Soltesz, MD ${ }^{\mathrm{b}}$}

Data from the Society for Thoracic Surgeons Adult Cardiac Surgery Database indicate that $10 \%$ to $15 \%$ of all cardiac surgery in the United States is performed on patients with significantly impaired left ventricular (LV) function (ejection fraction $<36 \%) .{ }^{1}$ It is well established that depressed left ventricular ejection fraction (LVEF) is a strong independent determinant of poor operative outcomes, including acute renal failure, longer ventilation times, and prolonged length of stay, ${ }^{2,3}$ and the development of perioperative low cardiac output syndrome/postcardiotomy shock (PCS) is the first manifestation heralding multiorgan dysfunction and mortality. PCS is diagnosed in $2 \%$ to $6 \%$ of patients undergoing cardiac surgery ${ }^{4}$ and most frequently develops in patients with impaired LVEF undergoing coronary revascularization in the setting of severe mitral insufficiency, poor targets, ventricular septal defect, or infarcted papillary muscle. Preoperative shock, older age, prior cardiac surgery, renal insufficiency, malnutrition, incomplete revascularization, and emergency status among others have been advanced as common risk factors. ${ }^{5,6}$ Under these circumstances, the preexisting stunned, hibernating, or acutely ischemic LV is subjected to the pathophysiology of the cardiopulmonary bypass circuit, to the ischemia mandated by crossclamping, and possibly to suboptimal cardioprotection, resulting in a dangerous combination of vasoplegia and low cardiac output. It follows that the historical standard of care management of PCS rests on the use of intravenous inotropes and vasopressors to counteract these 2 processes. Unfortunately, there is a paucity of evidence to guide physicians in the choice, dose, or combination of specific pharmacologic therapies to achieve better outcomes. Moreover, the use of these agents, particularly at the high doses often required to maintain adequate systemic blood pressure, incurs a price in terms of splanchnic and peripheral perfusion as well as potential arrhythmogenicity, and the combination of multiple agents is associated with worse

From the a Department of Cardiothoracic Surgery, Montefiore Medical Center, Bronx, NY; and bepartment of Thoracic and Cardiovascular Surgery, Cleveland Clinic Hospital, Cleveland, Ohio.

Received for publication Aug 9, 2021; accepted for publication Oct 4, 2021; available ahead of print Nov 10, 2021.

Address for reprints: Daniel J. Goldstein, MD, Department of Cardiothoracic Surgery, 3400 Bainbridge Ave, MAP 5 Bronx, NY 10467 (E-mail: dgoldste@montefiore. org).

JTCVS Open 2021;8:10-5

2666-2736

Copyright (C 2021 The Author(s). Published by Elsevier Inc. on behalf of The American Association for Thoracic Surgery. This is an open access article under the CC BY-NC-ND license (http://creativecommons.org/licenses/by-nc-nd/4.0/).

https://doi.org/10.1016/j.xjon.2021.10.001

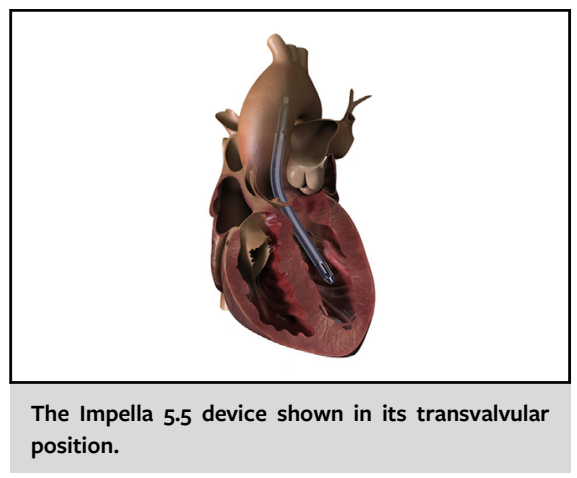

CENTRAL MESSAGE

We propose examining the use of preemptive LV unloading with a novel device, the Impella 5.5, as a new paradigm to prevent PCS and improve current outcomes of high-risk cardiac surgery.

See Commentary on page 16.

outcomes. ${ }^{7}$ Furthermore, these agents increase myocardial oxygen consumption ${ }^{8}$ (Table 1), an undesirable burden for the already impaired LV.

Because of its ease of insertion, ubiquitousness, and low cost, the intra-aortic balloon pump (IABP) remains the mainstay mechanical circulatory support deployed in these settings, either prophylactically or as therapy for PCS. While affording systolic afterload reduction and increased diastolic coronary perfusion, the IABP does not significantly augment cardiac output or unload the $\mathrm{LV}^{9}$; thus, its benefit relies on the presence of sufficient contractile function. Studies evaluating prophylactic use in high-risk surgery have yielded mixed results, with some randomized clinical trials failing to show a survival benefit, ${ }^{10-12}$ whereas 2 meta-analyses purport a benefit in the incidence of low cardiac output syndrome, hospital mortality, and intensive care unit length of stay. ${ }^{13,14}$ Recent societal guidance suggests that the "implantation of an IABP is not recommended in cases of severe LV or biventricular dysfunction as a primary treatment option in case of impossible CPB weaning or acute heart failure shortly after CPB weaning" (Class III, Level C). ${ }^{15}$ 
TABLE 1. Hemodynamic effects of drugs and devices used in the treatment of low cardiac output syndrome

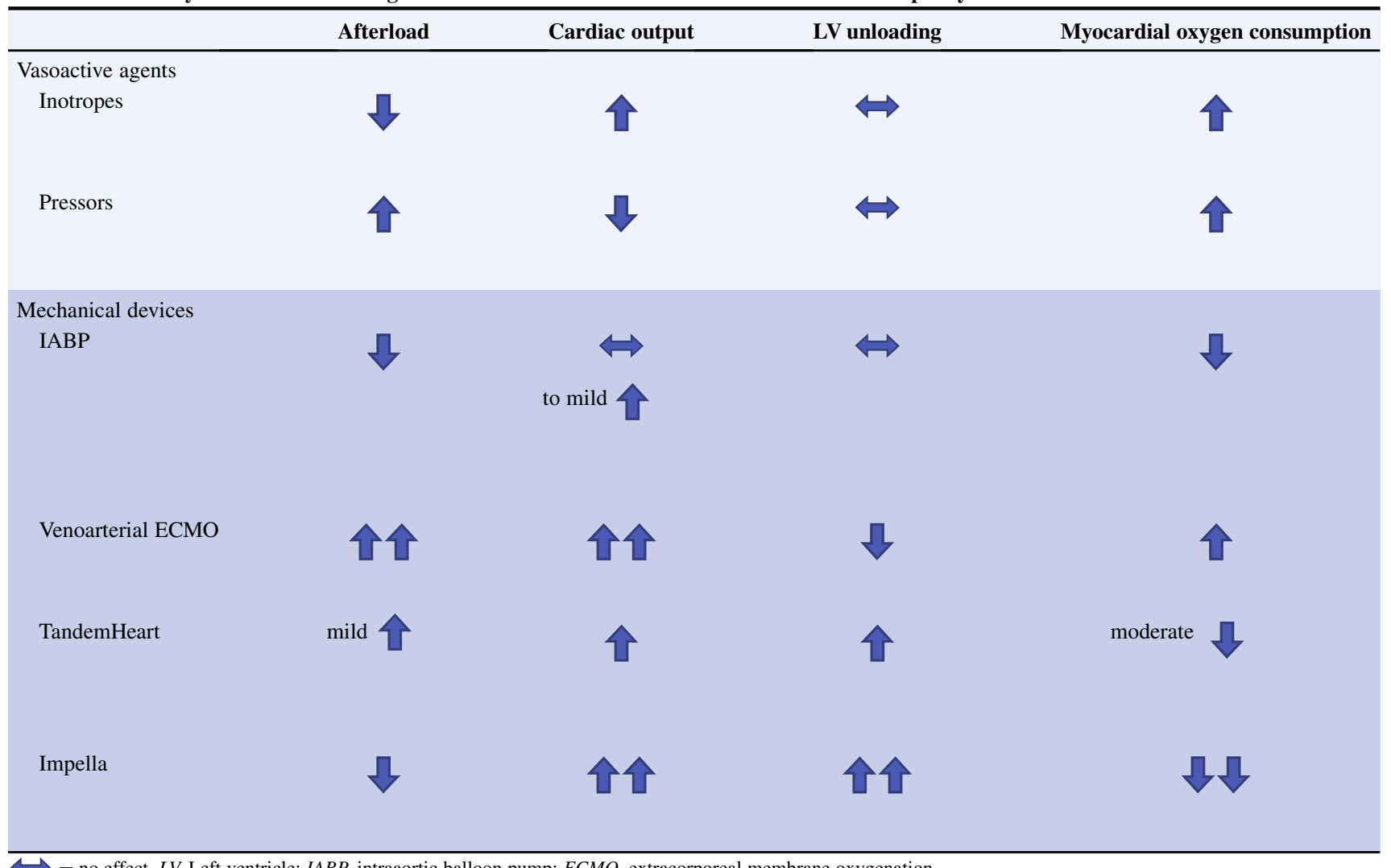

$=$ no effect. $L V$, Left ventricle; $I A B P$, intraaortic balloon pump; $E C M O$, extracorporeal membrane oxygenation.

When pharmacologic and IABP therapy fail to restore adequate hemodynamics, more invasive options are considered, most frequently, extracorporeal membrane oxygenation (ECMO). A recent meta-analysis surveying 31 observational studies evaluating the use of ECMO for PCS demonstrated dismal survival (36\%) and a high burden of reoperation for bleeding, renal failure, and neurologic events. ${ }^{16}$ Expert consensus designated the evidence for ECMO use in this setting as Class IIb, Level C indication. ${ }^{15}$

\section{POTENTIAL DESTINIES FOR PATIENTS WITH}

\section{LOW LEFT VENTRICULAR EJECTION FRACTION}

Although PCS remains a rare occurrence, the reported hospital mortality remains consistently high despite ongoing refinements in timing of institution, availability of several MCS devices, and improvements in critical care. Although severe LV dysfunction is the most salient risk factor associated with the development of PCS, patients with a reduced LVEF as a group are likely to benefit from cardiac surgery. ${ }^{2}$

It is possible that patients with severe LV dysfunction are denied conventional reparative surgery. On the one hand, a perceived lack of effective prophylaxis and therapy for PCS may lead to hesitancy about operating on this high-risk cohort. Second, and perhaps more pronounced, is the risk aversion that has occurred with healthcare public reporting not only on individual surgeons but also on their programs' ratings. This disincentivizes many healthcare providers from treating these patients, ${ }^{17}$ thereby leaving them with fewer treatment options.

Patients denied the option of reparative surgery follow 1 of 3 clinical paths. Some may be referred for percutaneous intervention, a strategy that in more than $50 \%$ of patients results in incomplete revascularization. ${ }^{18}$ Likewise, they may be referred for edge-to-edge percutaneous repair, which in one-third of patients results in no clinical benefit at 6 months. ${ }^{19}$ Alternatively, they may be ushered toward LV replacement therapies (LV assist device, transplantation). Finally, ongoing medical therapy and palliative care may be offered, with predictably unsatisfactory outcomes.

\section{PREEMPTIVE LEFT VENTRICULAR}

\section{UNLOADING: EXPLORING A NEW PARADIGM}

Can we provide a strategy that may increase the possibility of conventional reparative surgery for high-risk patients with severe LV dysfunction? To answer that question in the affirmative, we must first acknowledge that reliable prediction models for the development of PCS do not exist, and those advanced to anticipate survival after venoarterial ECMO carry modest discriminatory ability. ${ }^{20}$

Given the restricted predictability of PCS and the limited success of standard of care strategies for the management of 
PCS, a new approach is warranted. In this regard, it would be wise to borrow a page from the ongoing efforts by our colleagues in the interventional cardiology community where new thinking to limit postmyocardial infarct size has evolved. The inarguable success of door-to-balloon times while becoming a standard bearer for promoting optimal outcomes was not accompanied by changes in hospital mortality. ${ }^{21}$ This observation has led to efforts to examine preemptive (before reperfusion) LV unloading as a potential additive mitigator of infarct size and heart failure development. To this effect, the STEMI-Door-to-Unload Pilot trial demonstrated the safety and feasibility of an Impella device (Abiomed Inc, Danvers, Mass) to reduce infarct size and provided the impetus for an ongoing pivotal clinical trial. ${ }^{22}$ It is within this paradigm-shifting conceptual framework that a preemptive LV unloading strategy during high-risk conventional cardiac surgery may be explored. This concept has been used anecdotally in the setting of valvular surgery. ${ }^{23,24}$

\section{POTENTIAL UNLOADING TECHNOLOGIES}

The rationale for using a full $\mathrm{LV}$ unloading device in the setting of high-risk surgery is manifold: (1) It can potential reduce, spare, or allow weaning of toxic pressors that result in undesirable splanchnic and peripheral vasoconstriction $^{7,8} ;(2)$ it maintains end-organ perfusion by augmenting systemic output; (3) it allows time to metabolize inflammatory cytokines ${ }^{25}$ and to recover from the CPB-induced mitochondrial dysfunction mitochondrial function ${ }^{26}$; and (4) it allows time to assess recoverability of LV function. Three strategies based on current available technologies can be considered:

\section{Venoarterial ECMO}

Consisting of a right-sided drainage cannula and an arterial return, venoarterial ECMO unloads the right side of the heart and provides optimal cardiac output and end-organ perfusion. However, it results in increases in afterload, myocardial oxygen consumption, and stroke work, ${ }^{27}$ all undesirable effects in the setting of severe LV dysfunction.

\section{Tandem Heart}

The TandemHeart (Livanova Inc, London, UK) is a left atrial-to-aorta bypass system composed of a transseptal cannula, arterial cannula, and a centrifugal blood pump capable of generating up to $4 \mathrm{~L} / \mathrm{min}$ output. While increasing cardiac output and reducing myocardial oxygen consumption, it indirectly unloads the LV and has limited impact on stroke work. ${ }^{27,28}$

\section{Impella Pump}

The Impella (Abiomed Inc) family of pumps consist of an integrated transvalvular microaxial heart pump that relies on an inlet port in the LV cavity and an outflow above the aortic valve. It directly offloads the LV and decouples it from the aorta. By providing ongoing unloading of $\mathrm{LV}$ end-diastolic pressure and volume, it reduces myocardial oxygen consumption and stroke work while improving cardiac output. ${ }^{27}$

The physiologic effect of these pumps is depicted in Table 1. From the perspective of myocardial protection, the Impella pump theoretically has the most optimal characteristics for application in the setting of high-risk surgery. It increases coronary flow, ${ }^{29}$ and because of its inlet location within the cavity of the $\mathrm{LV}$, it provides the most profound LV unloading without a significant increase in afterload, thereby achieving the greatest reduction in myocardial oxygen consumption and LV pressure-volume area. ${ }^{28}$

\section{IMPELLA 5.5 FEATURES}

Designed for surgical placement via an axillary cutdown (Figure 1) or direct transaortic approach, it has a catheter length of $70 \mathrm{~cm}$, a cannula diameter of $21 \mathrm{~F}$, a motor diameter of 18F, and no pigtail residing in the LV (Figures 2 and 3). The pump can be actuated from 0 to $33,000 \mathrm{rpm}$ in 9 different speed settings ( $\mathrm{P} 0-\mathrm{P} 9)$ and can generate up to $6.2 \mathrm{~L} / \mathrm{min}$ of flow. The use of ceramic bearings within the pump allows for longer duration of support and enables the patient to ambulate. Unique features to this latest iteration are (1) the presence of a fiberoptic sensor technology that facilitates echocardiographic-guided repositioning without fluoroscopy (Figure 4); (2) the access to cloudbased remote monitoring; and (3) the ability to provide real-time measurements of $\mathrm{LV}$ end-diastolic pressure, mean aortic pressure, and native and total (native plus Impella flow) output (Figure 5).

In a recent whole-blood, mock-loop comparison with a temporary centrifugal circulatory device, the Impella 5.5

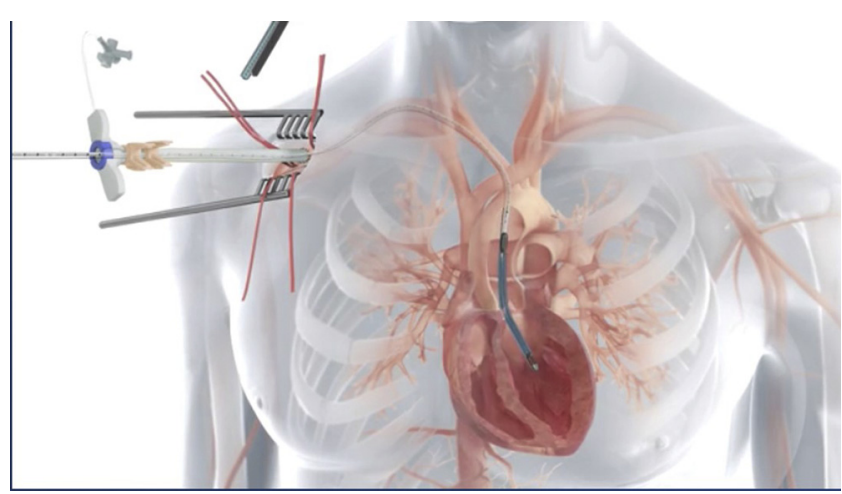

FIGURE 1. Transaxillary insertion of the Impella 5.5 device. After anastomosis of a 10-mm vascular graft to the axillary artery, fluoroscopy-guided advancement of the pump through an introducer and over a wire is undertaken. The inlet rests $5 \mathrm{~cm}$ below the aortic annulus. The short course of the device (unlike that of femorally based Impella devices) and superior fixation enhance positional stability and reduce catheter migration and hemolysis. The integral optical sensor provides real-time position status. Reproduced with permission from Abiomed Inc. 

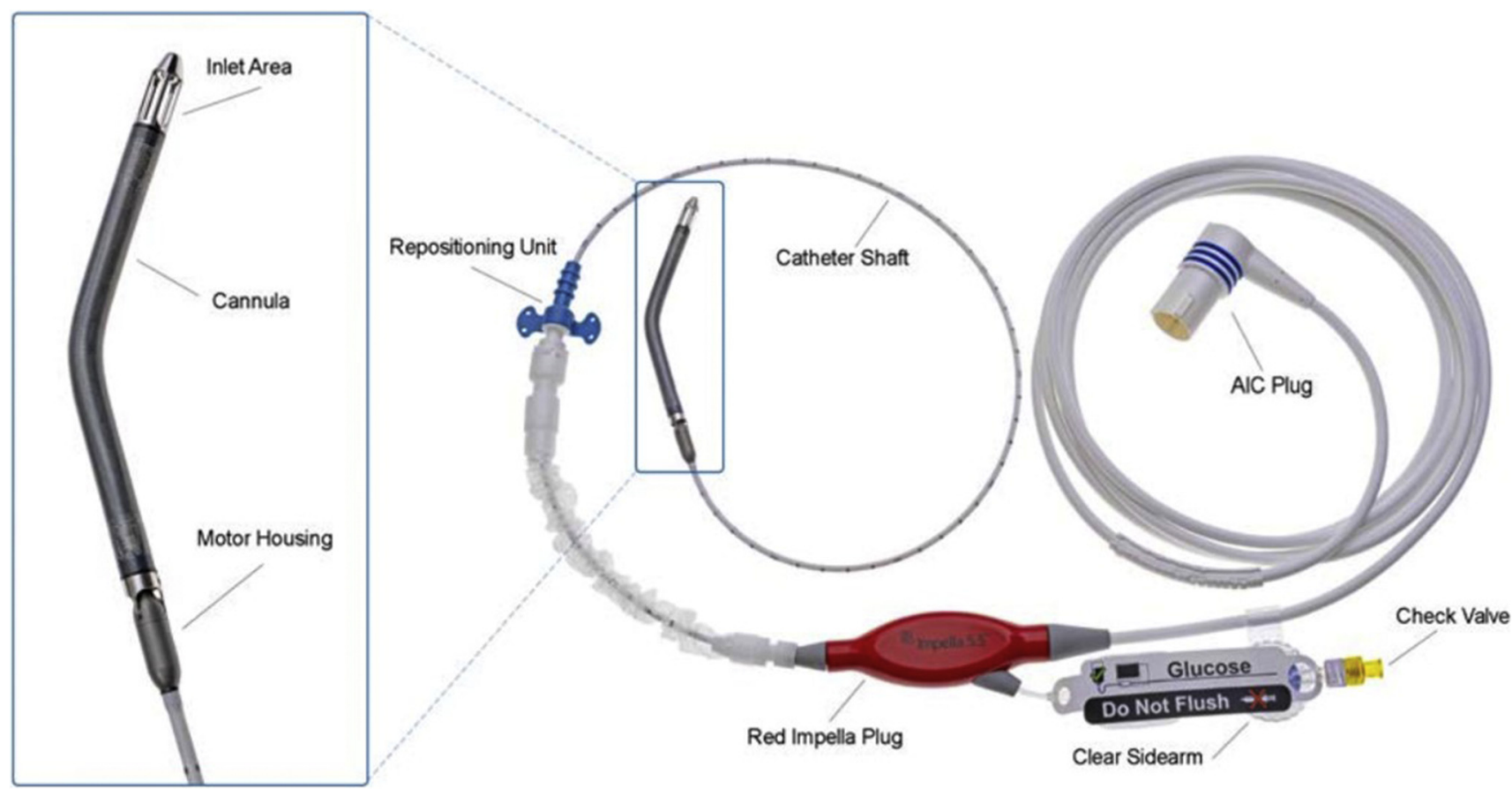

FIGURE 2. Impella 5.5 components. The catheter length is $70 \mathrm{~cm}$ with a cannula diameter of $21 \mathrm{~F}$, a motor diameter of $18 \mathrm{~F}$, and, unlike prior device iterations, no pigtail resides in the LV cavity. The lumen of the catheter shaft contains a purge lumen, a stainless-steel coil, a fiber-optic cable, and an electrical cable. A heparin-based purge solution is delivered constantly into the device lumen. Reproduced with permission from Abiomed Inc.

device was found to have good and equivalent hemocompatibility with similar lactate dehydrogenase activity, plasma-free hemoglobin, platelet degranulation, P-selectin alteration, decrease in platelet count, and microparticle generation. $^{30}$

\section{Clinical Experience With Impella 5.0/5.5 as Therapeutic Intervention}

Two recently published series document the initial clinical experience with the Impella 5.5 device. Bernhardt and colleagues ${ }^{31}$ reviewed the first 46 consecutive uses of the device after CE Mark approval. Main indications for use were acute on chronic heart failure in ischemic cardiomyopathy and acute myocardial infarction. Thirty percent of patients had a support device before Impella insertion. Mean support time was 16 days. Ninety-day survival was $72 \%$. More than one-third were weaned off support for LV recovery, and $40 \%$ were bridged to a durable pump. One-third of recipients were able to ambulate on Impella support. Seven patients developed pump thrombosis, and 20\% underwent pump exchange. In $22 \%$, pump migration was observed requiring repositioning or replacement. No ipsilateral upper-extremity ischemia was noted, and 1 cerebral vascular accident was documented. This initial European experience led to modifications in device design and fixation.

The early US experience was recently published. ${ }^{32}$ It encompasses the first 200 patients supported with this novel technology. The data were derived from a Food and Drug
Administration-mandated manufacturer-maintained quality database that captures baseline and procedural information and tracks outcomes until device removal. Median age

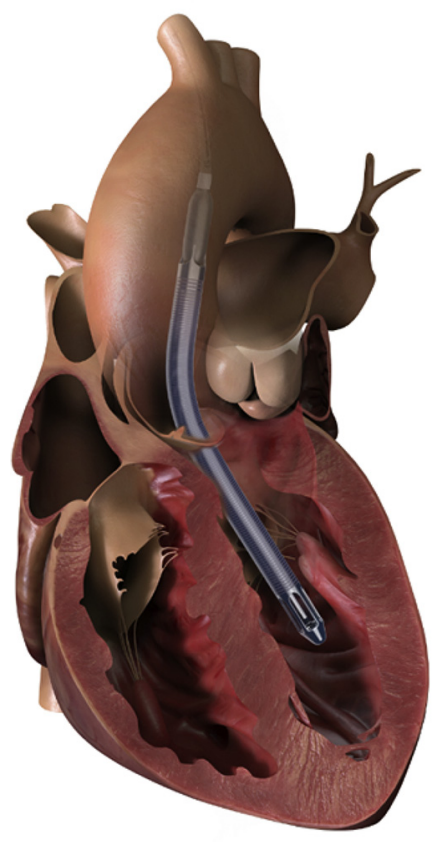

FIGURE 3. Impella 5.5 in its transvalvular position. Reproduced with permission from Abiomed Inc. 

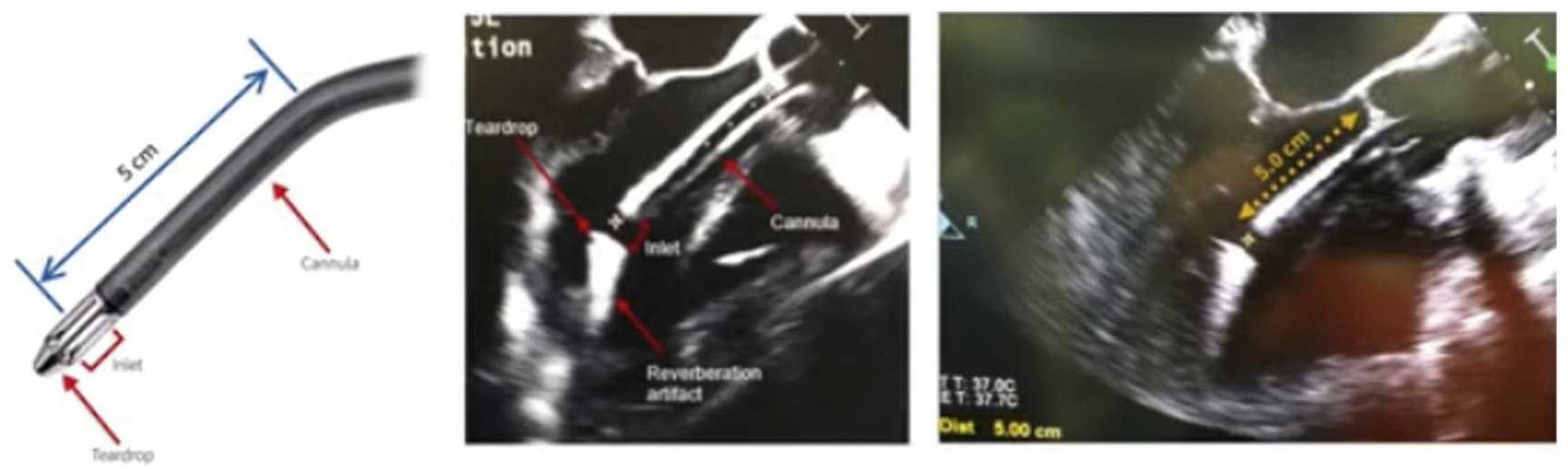

FIGURE 4. Echocardiographic midesophageal long-axis view depicting optimal placement of the Impella 5.5 within the LV cavity. The tip of the pump should be $5 \mathrm{~cm}$ below the aortic annuls without impinging on the mitral subvalvular apparatus or the intraventricular septum. Reproduced with permission from Abiomed Inc.

was 62 years, and most were male. The device was most frequently used for acute on chronic heart failure and acute myocardial infarction. A cohort of 33 patients with PCS were included, and it was used in 9 patients preemptively for high-risk coronary artery bypass grafting (details of this cohort are not provided). Adverse events included 1 cerebrovascular accident in a patient with LV thrombus. No device-related strokes, hemolysis, ipsilateral limb ischemia, or aortic valve injuries were seen. Seventy-four percent of patients were successfully bridged to recovery, transplant, or a durable device. Thirty-eight patients $(19 \%)$ died during support; of these, 16 were on concomitant ECMO. Survival to explant among the PCS cohort overall was $57.6 \%$; for the subset in which Impella support was used without ECMO, survival increased to $70.4 \%$, far higher than reported historically for this condition. ${ }^{16}$

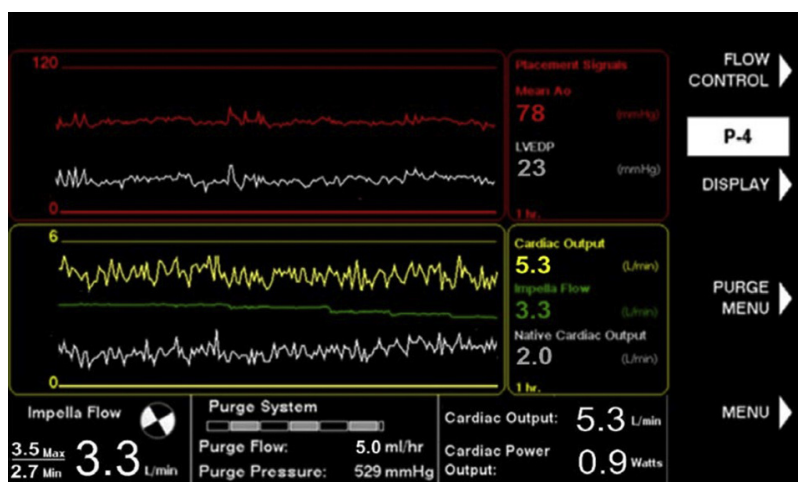

FIGURE 5. In addition to displaying placement and motor current signals (not shown), the Impella Controller screen provides continuous waveforms displaying mean aortic pressure, LV end-diastolic pressure, pump flow, and native and total cardiac outputs. Reproduced with permission from Abiomed Inc.

\section{Clinical Experience with Impella 5.0 as Preemptive Strategy}

No data have been published on the use of the latter Impella 5.5 device in this setting. The preemptive strategy paradigm has been examined in a clinical report describing the prophylactic use of Impella 5.0, a predecessor pump, during coronary artery bypass surgery in 13 patients with a mean LVEF of $20 \%$ and mean Society of Thoracic Surgeons mortality risk of $4.6 \%$. Need for vasoactive medications was minimal, and most patients were extubated within 48 hours and mobilized out of bed within 72 hours. Duration of support ranged from 1 to 8 days. No myocardial infarctions, renal failure, or mortality was observed, and 1 patient developed a stroke without permanent deficit. ${ }^{33}$

\section{PREEMPTIVE LEFT VENTRICULAR UNLOADING IN HIGH-RISK CARDIAC SURGERY: THE IMPELLA PROTECTED CARDIAC SURGERY TRIAL PILOT TRIAL}

The considerations outlined highlight the inability to predict PCS, the limited success of standard of care approaches to mitigate and treat PCS, and the issue of risk aversion instigated by public reporting that could result in hesitancy to offer conventional reparative surgery to high-risk patients. The availability of a direct LV unloading platform offering salutary effects on myocardial oxygen supply/ demand balance provides a unique opportunity to examine a new protective paradigm for patients with high-risk profiles and severe systolic LV dysfunction.

The Impella Protected Cardiac Surgery Trial is a prospective pilot study that will evaluate the preemptive use of Impella 5.5 device in patients undergoing high-risk cardiac surgery. It will enroll patients in 15 US and German centers. Because of the paucity of data, the trial's objectives are to investigate the feasibility of enrolling this cohort of sick patients and to collect data to determine event rates that will 
inform a large pivotal randomized clinical trial comparing preemptive Impella support against standard of care.

\section{Conflict of Interest Statement}

D.G. is a consultant for Abbott Inc and Abiomed Inc and serves as National Co-PI for the IMPACT Clinical Trial examining the use of the Impella 5.5 device in high-risk cardiac surgery, sponsored by Abiomed Inc. E.S. is a consultant for Abbott Inc, Atricure Inc, and Abiomed Inc, and serves as National Co-PIs for the IMPACT Clinical Trial examining the use of the Impella 5.5 device in high-risk cardiac surgery, sponsored by Abiomed Inc.

The Journal policy requires editors and reviewers to disclose conflicts of interest and to decline handling or reviewing manuscripts for which they may have a conflict of interest. The editors and reviewers of this article have no conflicts of interest.

\section{References}

1. Shahian DM, O’Brien SM, Filardo G, Ferraris VA, Haan CK, Rich JB, et al. The Society of Thoracic Surgeons 2008 cardiac surgery risk models: part 1-coronary artery bypass grafting surgery. Ann Thorac Surg. 2009;88(1 Suppl):S2-22.

2. Mahesh B, Peddaayyavarla P, Ong LP, Gardiner S, Nashef SAM. Cardiac surgery improves survival in advanced left ventricular dysfunction: multivariate analysis of a consecutive series of 4491 patients over an 18-year period. Eur J Cardiothorac Surg. 2016;50:857-66.

3. Thajli NM, Maltais S, Daly RC, Greason KL, Schaff HV, Dunlay SM, et al. Risk of conventional cardiac surgery among patients with severe left ventricular dysfunction in the era of mechanical circulatory support. J Thorac Cardiovasc Surg. 2018;156:1530-40.

4. Khorsandi M, Shaikhzerai K, Prasad S, Pessotto R, Walker W, Berg G, et al. Advanced mechanical circulatory support for postcardiotomy cardiogenic shock: a 20-year outcome analysis in a non-transplant unit. J Cardiothorac Surg. 2016; $11: 29$.

5. Smedira N, Blackstone E. Postcardiotomy mechanical support: risk factors and outcomes. Ann Thorac Surg. 2001;71(3 Suppl):S60-6.

6. Lomivorotov VV, Efremov SM, Kirov MY, Fominskiy EV, Karaskov AM. Low cardiac output syndrome after cardiac surgery. J Cardiothorac Vasc Anesth. 2017;31:291-308.

7. Samuels LS, Kaufman MS, Thomas MP, Holmes EC, Brockman SK, Wechsler AS. Pharmacological criteria for ventricular assist device insertion following postcardiotomy shock; experience with the Abiomed BVS system. $J$ Card Surg. 1999;14:288-93.

8. Vasu MA, O'Keefe DD, Kapellakis GZ, Vezeridis MP, Jacobs ML, Daggett WM, et al. Myocardial oxygen consumption and hemodynamics effects of dobutamine and other catecholamines. Surg Forum. 1975;26:227-9.

9. Burkhoff D, Naidu SS. The science behind percutaneous hemodynamic support: a review and comparison of support strategies. Cath Cardiovasc Interv. 2012;80: 816-29.

10. Metz D, Stiller M, Silber RE, Kroll H, Hofmann HS, Diez C. Prophylactic intraaortic balloon pumping in high-risk cardiac surgery patients. Med Klin Intensivmed Notfmed. 2011;106:125-31.

11. Ranucci M, Castelvecchio S, Biondi A, de Vincentiis C, Ballotta A, Varrica A, et al. A randomized controlled trial or preoperative intra-aortic balloon pump in coronary patients with poor left ventricular function undergoing coronary bypass surgery. Crit Care Med. 2013;41:2476-83.

12. Ferreira GSR, de Almeida JP, Landoni G, Vincent JL, Fominsky E, Gomes Galas FRB, et al. Effect of a perioperative intra-aortic balloon pump in highrisk cardiac surgery patients: a randomized clinical trial. Crit Care Med. 2018; 46:e742-50.

13. Pilarczyk K, Boening A, Jakob H, Langebartels G, Markewitz A, Haake N, et al. Preoperative intra-aortic counterpulsation in high-risk patients undergoing cardiac surgery: a meta-analysis of randomized clinical trials. Eur J Cardiothorac Surg. 2016;49:5-17.
14. Poirier Y, Voisine P, Plourde G, Rimac G, Perez AB, Costerousse O, et al. Efficacy and safety of perioperative intra-aortic balloon pump use in patients undergoing cardiac surgery: a systematic review and meta-analysis. Int J Cardiol. 2016;207:67-79.

15. Lorusso R, Whitman G, Milojevic M, Raffa G, McMullan DM, Boeken U, et al. 2020 EACTS/ELSO/STS/AATS expert consensus on post-cardiotomy extracorporeal life support in adult patients. Ann Thorac Surg. 2021;111:327-69.

16. Biancari F, Perroti A, Dalen M, Guerrieri M, Fiore A, Reichart D, et al. Metaanalysis of the outcome after postcardiotomy venoarterial extracorporeal membrane oxygenation in adult patients. J Cardiothorac Vasc Anesth. 2018;32: 1175-82.

17. Shahian D, Jacobs JP, Badhwar V, D'Agostino RS, Bavaria JE, Prager RL. Risk aversion and public reporting. Part 1: observations form cardiac surgery and in terventional cardiology. Ann Thorac Surg. 2017;104:2093-101.

18. Nagaraja V, Ooi Sze-Yuan, Nolan J, Large A, De Belder M, Ludman P, et al Impact of incomplete revascularization in patients with multivessel coronary artery disease: a systematic review and meta-analysis. J Am Heart Assoc. 2016;5 e004598.

19. Iung B, Messika-Zeitoun D. Transcatheter mitral valve repair in secondary MR New findings and new challenges. J Am Coll Cardiol. 2019;73:2133-4.

20. Worku B, Gaudino M, Avgerinos D, Ramasubbu K, Gambardella I, Gulkarov I, et al. A comparison of existing risk prediction models in patients undergoing venoarterial extracorporeal extracorporeal membrane oxygenation. Heart Lung. 2020;49:599-604.

21. Mennes DS, Peterson ED, Wang Y, Curtis JP, Messenger JC, Rumsfeld JS, et al Door-to-balloon time and mortality among patients undergoing primary PCI. $N$ Engl J Med. 2013;369:901-9.

22. Kapur N, Alkhouli MA, DeMartini TJ, Faraz H, George ZH, Goodwin MJ, et al Unloading the left ventricle before reperfusion in patients with anterior ST segment elevation myocardial infarction. Circulation. 2019;139:337-46.

23. Cohn WE, Morris CD, Frazier OH, Gregoric ID. Intraoperative tandem heart implantation as an adjunct to high-risk valve surgery. Tex Heart Inst J. 2007;34 457-8.

24. Hage F, Hage A, Smith S, Nagpal AD, Chu MWA. Prophylactic LVAD enabling high-risk mitral repair-extending beyond the guidelines. Innov (Phila). 2019; 14:573-6.

25. Warren OJ, Smith AJ, Alexiou C, Rogers PL, Jawad N, Vincent C, et al. The inflammatory response to cardiopulmonary bypass: Part 1 - mechanisms of pathogenesis. J Cardiothorac Vasc Anesth. 2009;23:223-31.

26. Lee SH, Doliba N, Osbakken M, Oz MC, Mancini D. Improvement of mitochondrial function after hemodynamic support with left ventricular assist devices in patients with heart failure. J Thorac Cardiovasc Surg. 1998;116:344-9.

27. Tehrani B, Basir M, Kapur N. Acute myocardial infarction and cardiogenic shock: should we unload the ventricle before percutaneous coronary intervention? Prog Cardiovasc Dis. 2020;63:607-22.

28. Burkhoff D, Naidu S. The science behind percutaneous hemodynamic support: a review and comparison of support strategies. Cath Cardiovasc Interv. 2012;80: 816-29.

29. Remmelink M, Sjauw KD, Henriques JP, de Winter RJ, Koch KT, van de Schaaf RJ, et al. Effects of left ventricular unloading by Impella Recover LP 2.5 on coronary hemodynamics. Catheter Cardiovasc Interv. 2007;70: 532-7.

30. Rika-Moiia Y, Mengtang L, Ivich A, Muslmani S, Kern KB, Slepian MJ. Impella 5.5 versus Centrimag: a head-to-head comparison of device hemocompatibility. ASAIO J. 2020;66:1142-51.

31. Bernhardt A, Potapov E, Schibilisky D, Ruhparwar A, Tschöpe C, Spillmann F et al. First in man evaluation of a novel circulatory support device: early experience with the Impella 5.5 after CE mark approval in Germany. J Heart Lung Transplant. 2021;40:850-5.

32. Ramzy D, Anderson M, Batsides G, Ono M, Silvestry S, D’Alessandro DA, et al Early outcomes of the first 200 US patients treated with Impella 5.5: a novel temporary left ventricular assist device. Innov (Phila). 2021;16:365-72.

33. Ranganath NK, Nafday HB, Zias E, Hisamoto K, Chen S, Kon ZN, et al. Concomitant temporary mechanical support in high-risk coronary artery bypass surgery. J Card Surg. 2019;34:1569-72.

Key Words: high-risk cardiac surgery, low cardiac output syndrome, postcardiotomy shock, severe left ventricular dysfunction, temporary mechanical circulatory support 